\title{
SINGLE-PHASE AND TWO-PHASE SECONDARY COOLANTS: SIMULATION AND EVALUATION OF THEIR THERMOPHYSICAL PROPERTIES
}

\author{
P. S. G. MEDEIROS ${ }^{1}$, C. R. F. BARBOSA ${ }^{1}$ e F. A. O. FONTES ${ }^{1}$
}

${ }^{1}$ Programa de Pós-Graduação em Engenharia Mecânica, Grupo de Estudo em Sistemas Térmicos (GEST) Universidade Federal do Rio Grande do Norte (UFRN).

falecom-pedro@hotmail.com-cleiton@ufrnet.br-franciscofontes@uol.com.br

Artigo submetido em fevereiro/2011 e aceito em junho/2011

\section{ABSTRACT}

This paper makes a comparative analysis of the thermophysical properties of ice slurry with conventional single-phase secondary fluids used in thermal storage cooling systems. The ice slurry is a two-phase fluid consisting of water, antifreeze and ice crystals. It is a new technology that has shown great energy potential. In addition to transporting energy as a heat transfer fluid, it has thermal storage properties due to the presence of ice, storing coolness by latent heat of fusion. The single-phase fluids analyzed are water- $\mathrm{NaCl}$ and water-propylene glycol solutions, which also operate as carrier fluids in ice slurry. The presence of ice changes the thermophysical properties of aqueous solutions and a number of these properties were determined: density, thermal conductivity and dynamic viscosity. Data were obtained by software simulation. The results show that the presence of $10 \%$ by weight of ice provides a significant increase in thermal conductivity and dynamic viscosity, without causing changes in density. The rheological behavior of ice slurries, associated with its high viscosity, requires higher pumping power; however, this was not significant because higher thermal conductivity allows a lower mass flow rate without the use of larger pumps. Thus, the ice slurry ensures its high potential as a secondary fluid in thermal storage cooling systems, proving to be more efficient than single-phase secondary fluids.

KEY-WORDS: Ice Slurry, Secondary Fluids, Thermophysical Properties, Thermal Storage Cooling. 


\section{SINGLE-PHASE AND TWO-PHASE SECONDARY COOLANTS: SIMULATION AND EVALUATION OF THEIR THERMOPHYSICAL PROPERTIES}

\section{INTRODUCTION}

The refrigerant fluids used in refrigeration and air conditioning processes are an environmental and economic concern, mainly in large systems with high thermal loads. In the latter case, in addition to the non-feasibility of the project, owing to the high costs of such a large system (PRUZAESKY, 2008), the use of vast amounts of refrigerant fluid and possible leakages could cause environmental damage (EGOLF, 2004). An effective alternative is to use an indirect expansion refrigeration system with thermal storage, which contributes to more efficient refrigeration in more compact systems. This results in economy, operational flexibility and a significant reduction in the amount of refrigerant fluid. The thermal storage process enables cold generation and storage at night. Moreover, there are no thermal loads, energy costs are lower and the primary refrigeration system is more efficient. The stored coolness is used during the day, mainly at times of high thermal load and peak energy demand (ASHRAE, 2008).

A refrigeration system with thermal storage uses thermal fluid to transport coolness from the thermal storage tank to the refrigeration site, and the selection of this fluid is extremely important for the thermal efficiency of the process. It is known that the thermal and transport properties of water would qualify it as a thermal fluid, except for the fact that most industrial refrigeration processes work at temperatures well below its melting point. Thus, the addition of a soluble antifreeze agent produces a homogeneous solution capable of solidifying at temperatures below the melting point of purified water, forming a secondary fluid.

Adding antifreeze to water reduces the thermophysical properties of the solution compared to purified water, leading to losses of thermal conductivity and specific heat (ASHRAE, 2009; MELINDER, 2007). These losses result in lower thermal inertia in the fluid, in addition to a reduction in heat transfer capacity and thermal energy storage.

One of the alternatives for cold storage is the production of ice in tanks. Its high thermal energy density and elevated heat of fusion make ice an effective material for storing thermal energy, reducing storage volume by a factor of 2 to 10 times (MARTINEZ, 2005). Another solution is the use of phase change materials (PCMs) encapsulated in thermal storage tanks, which store coolness through latent heat of fusion (GUZMAN, 2004). However, both ice and encapsulated PCMs are restricted in tanks and are not pumped, requiring a secondary fluid to transport coolness from the thermal storage tank to the refrigeration medium.

The idea of using latent heat of fusion as a thermal accumulator and transporting it to transfer energy is only possible through phase change secondary fluids, that is, two-phase fluids. The justification for using phase change secondary fluids is to "take advantage of the difference in enthalpy of vaporization or fusion" (MARTINEZ, 2005, p. 28). Two fluids provide these conditions: $\mathrm{CO}_{2}$ and ice slurry.

$\mathrm{CO}_{2}$ is an atoxic, nonflammable gas used as primary and secondary refrigerant fluid. Its application is restricted due to its low viscosity, low mass flow rate and high operating pressures (KRUSE, 2000). The main application of $\mathrm{CO}_{2}$ is in transcritical refrigeration cycles. 
Ice slurry is a suspension of ice crystals dispersed in a carrier fluid composed of water and antifreeze. The mass concentration of ice depends on the technology used in slurry production, normally ranging from $2 \%$ to $10 \%$, or higher (ASHRAE, 2008). According Egolf and Kaunffeld (2005), thermophysical properties of ice slurry are a function of the geometry and granulometry of the crystals, with mean diameter of less than $1 \mathrm{~mm}$ (Figure 1).

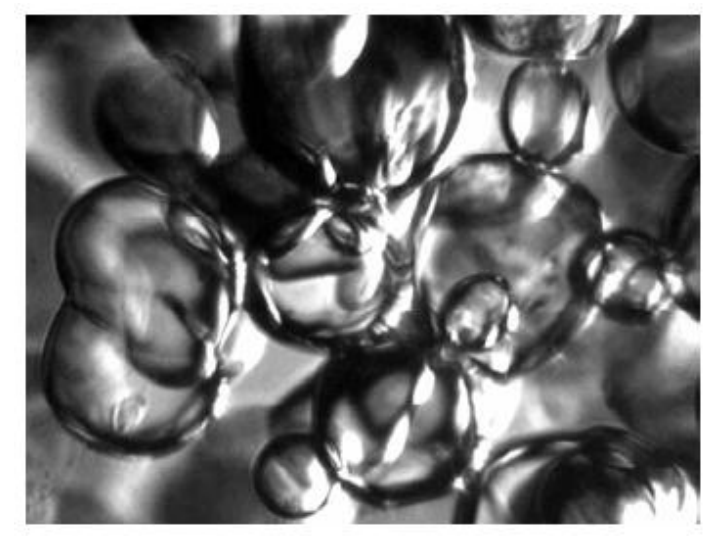

Fig. 1 - A microphotograph with fifteen particles is shown. The dimension of the picture is $1061 \mu \mathrm{m} \mathrm{x}$ $762 \mu \mathrm{m}$ (EGOLF, KAUNFFELD, 2005)

The main advantage of ice slurry is its high cooling capacity, resulting in a reduction in thermal storage tank size, mass flow rate in the heat exchangers and pipe diameter (MELINDER, 2007). Given that it is a relatively new phenomenon, there are a number of studies analyzing its characteristics. The aim of this study was to assess the thermophysical properties of ice slurry for commercial applications in refrigeration processes with thermal storage, compared to conventional single-phase fluids.

\section{METHODOLOGY}

The thermophysical property data of the secondary fluids were obtained using SecCool (figure 2), freeware software designed by the Department of Mechanical Engineering at the University of Denmark in 2007. This software contains a library with the thermophysical properties of secondary fluids based mainly on the experimental parameters of ASHRAE (American Society of Heating, Refrigeration and Air-Conditioning Engineers) and Ake Melinder, a researcher in the Department of Energy Technology at the Royal Institute of Technology of Sweden, from his works of postgraduate (Melinder, 2007).

The SecCool works from correlations of experimental values of each database. A statistical analysis is performed by the software, determining the polynomial equation that governs the behavior of the solution. The thermophysical properties are calculated from input data: temperature, concentration of antifreeze (single-phase fluids) or ice concentration (ice slurry). The output data are density, thermal conductivity and dynamic viscosity. 
The ice slurries (two-phase fluid) were compared with conventional single-phase fluids, quantifying the percentage difference between their properties. The single-phase secondary fluids analyzed were water- $\mathrm{NaCl}$ solutions (sodium chloride) and water-propylene glycol, at mass solute of $20 \%$ and $35 \%$ respectively. The ice slurries studied were the previously mentioned single-phase solutions with $10 \%$ by weight of ice added.

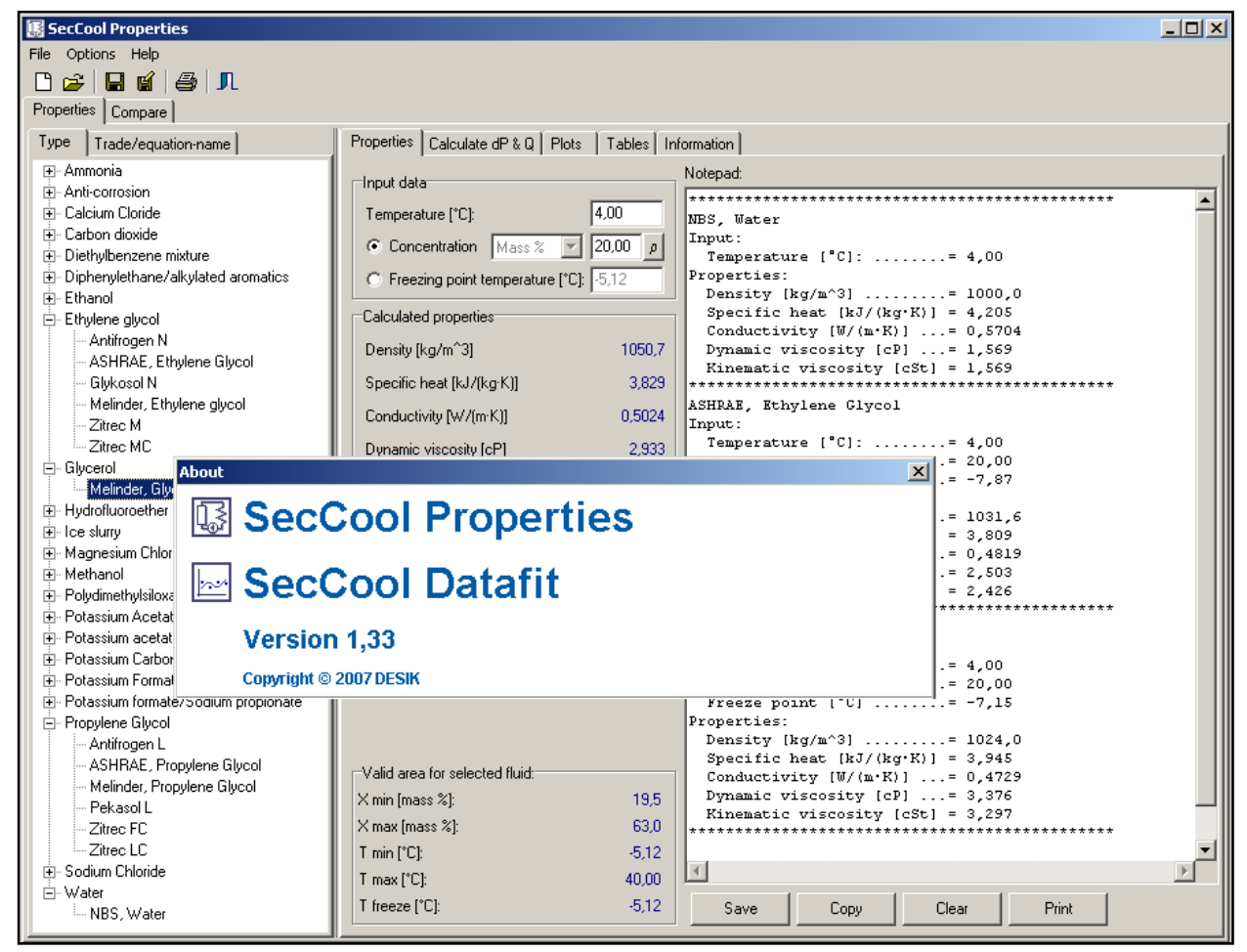

Fig. 2 - SecCool's Screen

The following thermophysical properties were examined in the sample: density (thermodynamic property), thermal conductivity and dynamic viscosity (transport properties). These properties refer to the amount of fluid in the tank, its heat transfer capacity and outflow resistance. Analysis temperature of the properties for all the samples is $-16,5{ }^{\circ} \mathrm{C}$, corresponding to the temperature at which the ice slurry tends to solidify for the value cited as a function of additive concentration. This analysis temperature lies within the values used in cold storage systems, about $-17^{\circ} \mathrm{C}$ or $0{ }^{\circ} \mathrm{F}$ (DOSSAT, HORAN, 2002).

Sodium chloride and propylene glycol were chosen as antifreeze agents for the wide commercial application of these products. Despite being corrosive, sodium chloride is commonly used as an additive owing to its good antifreeze properties. Purified propylene glycol (1,2-propanediol) is a nontoxic glycol alcohol with a melting point at $-59{ }^{\circ} \mathrm{C}$ and low vapor pressure (DOW CHEMICAL, 2011), which favors its application as an antifreeze agent, in addition to being an alternative to ethylene glycol, a toxic glycol alcohol (FINK, 2003). 
Using these data, we constructed tables and graphs to determine and explore the interference of ice in single-phase fluids.

\section{RESULTS AND DISCUSSION}

The numerical values of the thermophysical properties of the fluids analyzed, obtained in the SecCool (2007), are shown in table 1.

Table 1. Thermophysical properties of the single-phase fluids and ice slurries

\begin{tabular}{l|ccc}
\hline \multirow{2}{*}{ Sample } & \multicolumn{3}{|c}{ Thermophysical Properties } \\
\cline { 2 - 4 } & $\begin{array}{c}\text { Density } \\
\left(\mathrm{kg} / \mathrm{m}^{3}\right)\end{array}$ & $\begin{array}{c}\text { Thermal Conductivity } \\
\left(\mathrm{W} / \mathrm{m} .{ }^{\circ} \mathrm{C}\right)\end{array}$ & $\begin{array}{c}\text { Dynamic Viscosity } \\
\text { (cP) }\end{array}$ \\
\hline Water- $\mathrm{NaCl}$ & 1163,1 & 0,5217 & 4,97 \\
Ice Slurry-NaCl & 1132,5 & 0,6330 & 7,13 \\
Water-Prop. glycol & 10424 & 0,3959 & 26,74 \\
Ice slurry-Prop. glycol & 1027,9 & 0,4851 & 34,44
\end{tabular}

Source: SECCOOL, 2007

Table 2 demonstrates the percent difference between the thermophysical properties of ice slurries and single-phase fluids, where they are grouped according to type of carrier fluid, that is, the additive used as antifreeze agent.

Table 2. Percent difference between ice slurry and conventional fluids

\begin{tabular}{l|ccc}
\hline \multirow{2}{*}{ Relation } & \multicolumn{3}{c}{ Thermophysical Properties } \\
\cline { 2 - 4 } & Density (\%) & Thermal Conductivity (\%) & Dynamic Viscosity (\%) \\
\hline Ice slurry/Water-NaCl & $-2,63$ & 21,33 & 43,69 \\
$\begin{array}{l}\text { Ice slurry / Water- } \\
\text { Prop. glycol }\end{array}$ & $-1,39$ & 22,53 & 28,80 \\
\hline
\end{tabular}

Each property was analyzed separately as a function of the antifreeze solute used in the solution. 


\section{Density}

Density is defined as the weight per unit volume of a material. It is desirable that secondary fluids have the highest density possible, since, in addition to reducing the size of thermal storage tanks, exhibits more efficient heat transfer properties, in terms of thermal diffusivity.

Single-phase fluids have higher density than water because the solutes are denser. Figure 3 gives a graphic illustration of the density values of single-phase and two-phase solutions.

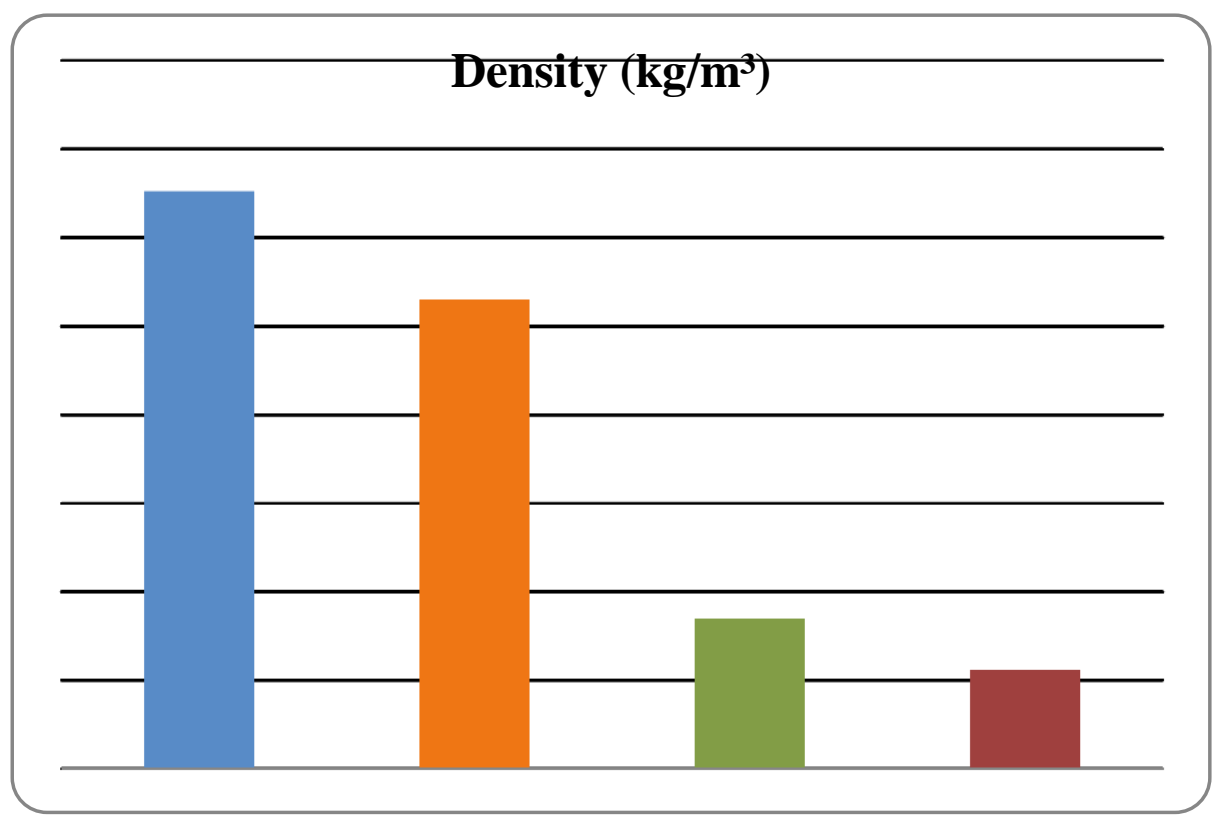

Fig. 3 - Density of single-phase and two-phase solutions

The presence of ice in single-phase fluids, even at microscopic size and in small amounts, alters the density of the solution. This occurs because ice has a density of $917 \mathrm{~kg} / \mathrm{m}^{3}$ at $0{ }^{\circ} \mathrm{C}$ (BEJAN, KRAUS, 2003), that is, less dense than purified water, $999,9 \mathrm{~kg} / \mathrm{m}^{3}$ at $1{ }^{\circ} \mathrm{C}$ (SECCOOL, 2007). Tables 1 and 2 show that the density of ice slurries is lower than that of single-phase fluids. However, the addition of $10 \%$ ice by weight did not significantly alter the values: the density of two-phase solutions was reduced by $2,63 \%$ for the water- $\mathrm{NaCl}$-ice solution and by $1,39 \%$ for water-propylene glycol-ice.

Thus, as there were no significant alterations in density with the addition of ice, the size of thermal storage tanks did not change with the same amount of fluid mass.

\section{Thermal Conductivity}


Thermal conductivity is a transport property characteristic of each substance, which indicates the rate at which a given material can transport energy under conditions determined by geometry and temperature. The heat transfer mechanism in a solid is well defined and occurs through vibrations in its crystalline structure. In the case of metals, it is complemented by the movement of free electrons present in the network, while thermal exchange in liquid substances is similar to that of gases, that is, through molecular collisions and molecular diffusion (BEJAN, KRAUS, 2003).

In this study we analyzed single-phase and two-phase secondary fluids, in which the mechanisms involved in heat transmission are different. For single-phase fluids, transmission occurs through sensible heat exchange until the melting or boiling point of a liquid is reached. In ice slurry there are simultaneous sensible and latent heat exchanges in the fluid, characterizing a heat transfer in a multiphase system, that is, with a liquid phase (waterantifreeze) and a solid phase (ice).

The energy flux through the ice crystals are due by the mechanisms of convection and absorption of latent heat of fusion, which both are functions of the mass flow of crystals (NATERER, 2003). Thus, the total heat flux in the ice slurry is only determined when there is phase change under flow. However, in this paper, only the thermal conductivity of these secondary coolants (single-phase and two-phase) without phase change is analyzed, disregarding the convective currents.

Ice slurry has a thermal conductivity higher than the single-phase fluids. This increase is due to the presence of ice crystals in solution. For comparative purpose, the thermal conductivity of ice at $0{ }^{\circ} \mathrm{C}$ is $2,25 \mathrm{~W} / \mathrm{m} .{ }^{\circ} \mathrm{C}$ (BEJAN, KRAUS, 2003), and thermal conductivity of purified water at $1{ }^{\circ} \mathrm{C}$ is $0,5642 \mathrm{~W} / \mathrm{m} .{ }^{\circ} \mathrm{C}$ (SECCOOL, 2007); a difference of $75 \%$.

The water- $\mathrm{NaCl}$ and water-propylene glycol single-phase fluids have thermal conductivity of $0,5217 \mathrm{~W} / \mathrm{m} .{ }^{\circ} \mathrm{C}$ (SECCOOL, 2007) and $0,3959 \mathrm{~W} / \mathrm{m} .{ }^{\circ} \mathrm{C}$ (SECCOOL, 2007), respectively; while ice slurry- $\mathrm{NaCl}$ and ice slurry-prop. glycol have $0,6330 \mathrm{~W} / \mathrm{m} .{ }^{\circ} \mathrm{C}$ (SECCOOL, 2007) and $0,4851 \mathrm{~W} / \mathrm{m} .{ }^{\circ} \mathrm{C}$ (SECCOOL, 2007), respectively; at $-16,5^{\circ} \mathrm{C}$ for all fluids. This shows why the addition of ice to single-phase fluids significantly increased thermal conductivity, by $21,33 \%$ and $22,53 \%$ for water- $\mathrm{NaCl}$-ice and water-propylene glycol-ice, respectively. Figure 4 gives a graphic illustration of thermal conductivity values obtained for single-phase and twophase fluids.

Another important factor for the increased thermal conductivity of ice slurries is the greater thermal exchange area of ice crystals. Single-phase solution conductivity is related to the fine ice particles dispersed in the carrier fluid and is a function of their respective size (TICONA, 2007).

Therefore, the thermal conductivity of ice slurry is associated to the crystals, since latent heat of fusion and the larger heat exchange area are determining factors for enhanced heat transmission efficiency compared to conventional single-phase fluids. 


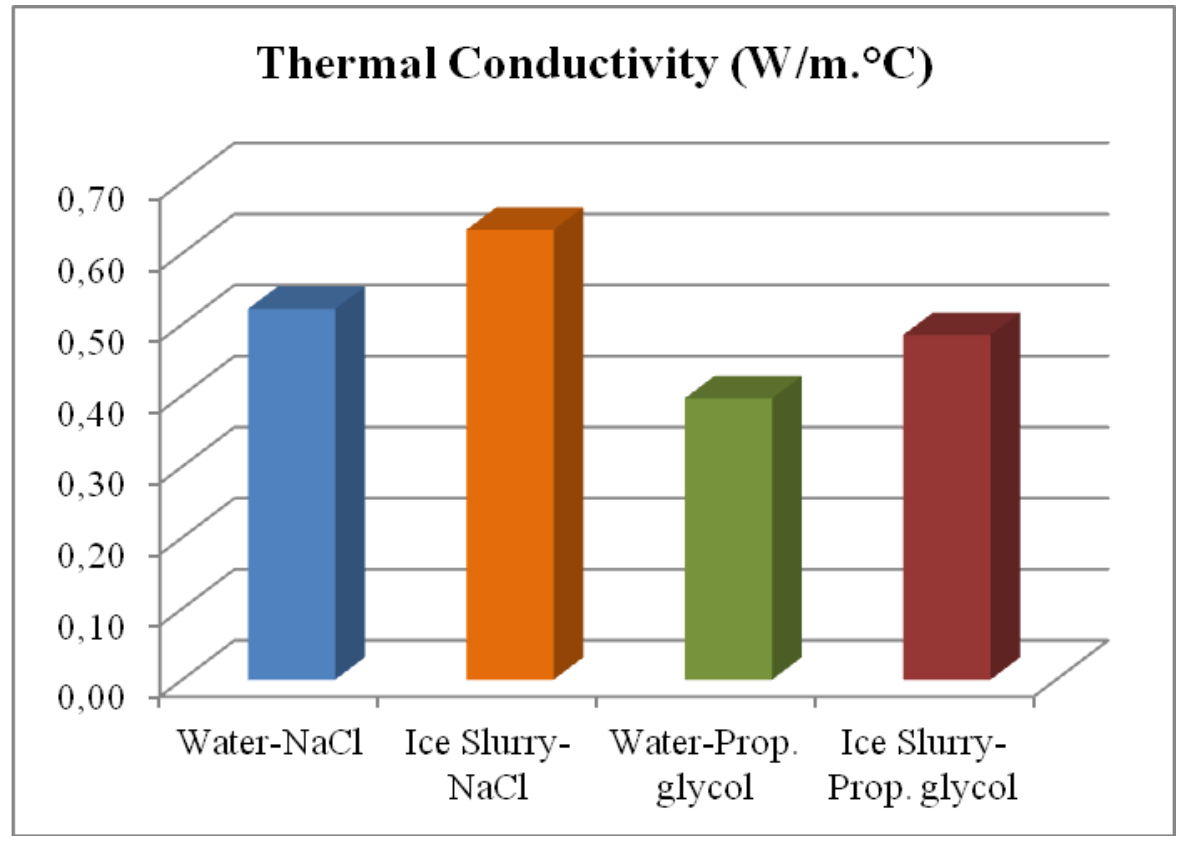

Fig. 4 - Thermal conductivity of single-phase and two-phase fluids

\section{Dynamic Viscosity}

Dynamic viscosity is a transport property related to the internal outflow resistance of a fluid, caused by cohesive forces present between fluid molecules. Thus, as was described in the thermal conductivity section, ice slurry is analyzed as a multiphase system, exhibiting different behavior from that of single-phase fluids submitted to outflow.

Unlike single-phase fluids, multiphase fluids require higher outflow velocities, mainly to sustain the solid particles in suspension. The outflow of a single-phase fluid is homogeneous for all the velocities applied, in contrast to multiphase fluids that behave heterogeneously, exhibiting the rheological properties of non-Newtonian fluids (CROWE, 2006).

Ice slurry is a non-Newtonian fluid and is treated rheologically as a stable viscoplastic fluid (NIEZGODA-ZELASKO, ZELASKO, 2009). Single-phase systems behave like a Newtonian fluid, with constant dynamic viscosity for a given pressure and temperature. Multiphase systems do not exhibit constant dynamic viscosity, that is, there is no constant relationship between shear stress and shear rate. Moreover, they consider temperature and pressure to determine the viscosity of multiphase fluids (CHHABRA, RICHARDSON, 2008).

In this analysis, it is considered that the pressure conditions are the same for all the fluids. The dynamic viscosity of ice slurries is analyzed considering that slurries behave like a Newtonian fluid. Tables 1 and 2 show that ice slurry viscosity is higher than in single-phase fluids, that is, $43,69 \%$ for the water- $\mathrm{NaCl}$ fluid and $28,80 \%$ for the water-propylene glycol ice solution. Figure 5 illustrates the dynamic viscosities of the secondary fluids studied. 


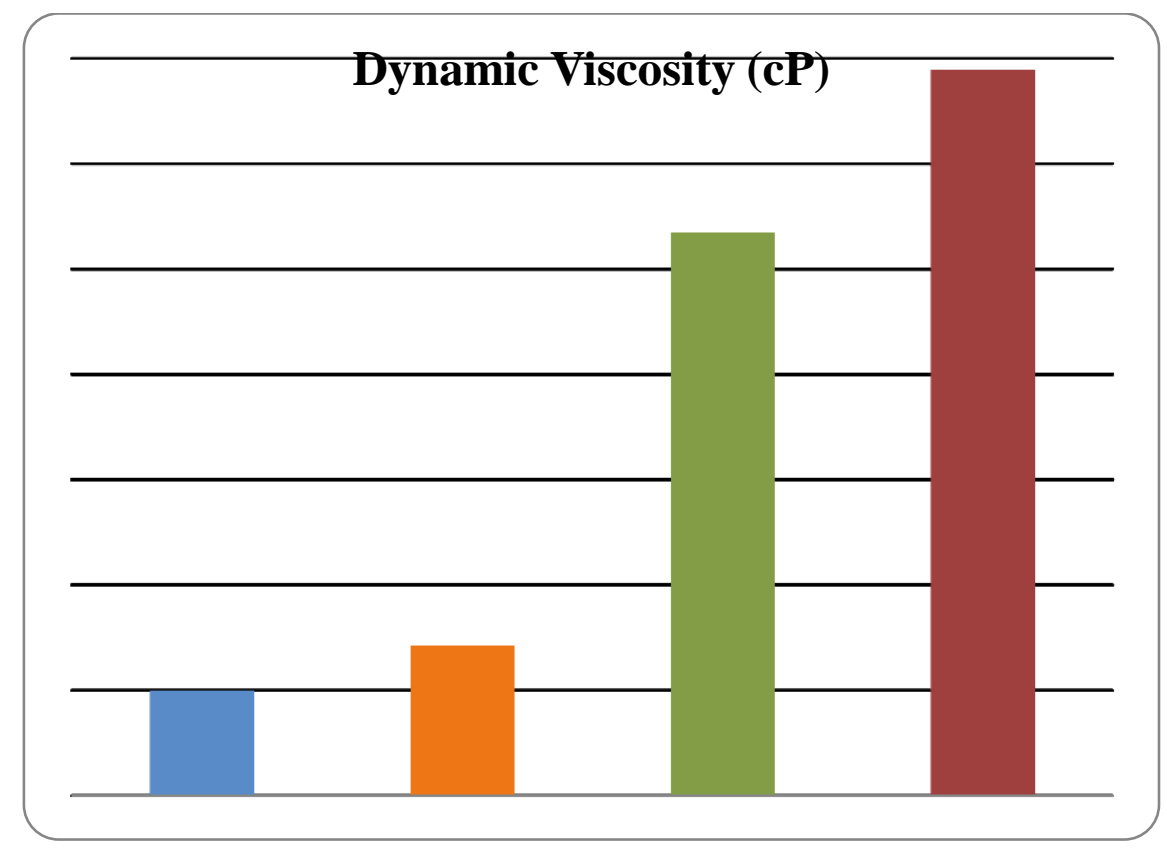

Fig. 5 - Dynamic viscosity of the secondary fluids analyzed

These increases are considerable, mainly for the slurry that uses sodium chloride as antifreeze agent. The high increases in slurry viscosities are related to the granulometry and geometry of the ice crystals and their interactions with antifreeze additives. Despite being microscopic crystals, they have a direct influence on viscosity and pumping difficulty.

Therefore, it can be confirmed that for the same outflow conditions of single-phase and two-phase fluids, ice slurries need greater pumping power than single-phase fluids. This can be explained by the high viscosity contained in slurries concomitant with greater outflow velocities.

\section{CONCLUSIONS}

After comparative analysis of the conventional single-phase secondary fluids and ice slurries, it was concluded that their thermophysical properties show different characteristics for a more efficient use in heat transfer processes.

The density of ice slurries is slightly lower than in single-phase fluids because ice is less dense than water. The reduction is not significant and there are no interferences in thermal efficiency or in the constructive characteristics of storage tanks used in the refrigeration process.

The presence of ice as a phase change material in two-phase fluids promotes an accumulation of thermal energy through latent heat of fusion, which ensures larger thermal conductivity compared to single-phase fluids. Microscopic crystals offer a greater heat exchange area, further increasing their power to transfer energy. 
Since it is a two-phase fluid, ice slurry exhibits peculiar outflow characteristics, in contrast to single-phase fluids, which are Newtonian, mainly because they display much higher and variable viscosity, given the temperature and pressure conditions. The rheological phenomena of the slurry are justified by the presence of ice, which alters all the outflow conditions, requiring greater flows.

From the energetic viewpoint, ice slurry is superior to single-phase fluids. Considering the same conditions for the same refrigeration effects, the mass flow of the slurry is lower, resulting in lower pumping power and smaller pipe diameter. Its thermal storage effect is greater, which leads to a more rational and efficient use of energy with smaller amounts of fluid in smaller tanks. Even though it needs greater outflow velocities and exhibits higher viscosity, the refrigeration system does not require high power pumps, mainly due to lower fluid flow.

The simulation of the thermophysical properties of single-phase and two-phase fluids provides an overview of how ice slurry is superior to conventional fluids. The isolated data of thermophysical properties characterize the fluid and only show a preview of their behavior in energy thermal storage. The interaction of thermophysical properties is who sets the real behavior of each fluid in cool thermal storage, and it will can only be measured by performing experiments that attempt to represent the effects of the properties in the accumulation of thermal energy.

\section{REFERENCES}

1. ASHRAE. Fundamentals Handbook. Atlanta: American Society of Heating, Refrigeration and Air Conditioning, 2009.

2. HVAC Systems and Equipment. Atlanta: American Society of Heating, Refrigeration and Air Conditioning, 2008.

3. BEJAN, A., KRAUS, A. D. Heat Transfer Handbook. Hoboken: John Wiley \& Sons, 2003.

4. CHHABRA, R. P., RICHARDSON, J. F. Non-Newtonian Flow and Applied Rheology. 2nd edition. Oxford: Butterworth Heinemann, 2008.

5. CROWE, C. T. (editor). Multiphase Flow Handbook. Boca Raton: CRC Press, 2006.

6. DOSSAT, R. J., HORAN, T. J. Principles of Refrigeration. New Jersey, Prentice Hall, 2002.

7. DOW CHEMICAL. Dow Propylene Glycol, Industrial Grade: Technical Data Sheet. Available in:

http://msdssearch.dow.com/PublishedLiteratureDOWCOM/dh 0037/0901b80380037a64. pdf?filepath=propyleneglycol/pdfs/noreg/117-01540.pdf\&fromPage=GetDoc. Access: July, $20^{\text {th }} 2011$.

8. EGOLF, P. W. Ice Slurry: a promising technology. International Institute of Refrigeration, pp. 1-3, July 2004.

9. EGOLF, P. W., KAUFFELD, M. From physical properties of ice slurries to industrial ice slurry applications. International Journal of Refrigeration, vol. 28, pp. 4-12, 2005. 
10. FINK, J. K. Oil Field Chemical. Burlington: Gulf Professional Publishing, 2003.

11. KRUSE, H. Refrigerant use in Europe. ASHRAE Journal, pp. 16-24. September 2000.

12. MARTINEZ, L. C. C. Determinação Experimental dos Coeficientes de Transporte da Pasta de Gelo em Trocadores de Calor de Placas. Rio de Janeiro, 2005. M.Sc. Thesis, Pontifícia Universidade Católica, 2005.

13. MELINDER, A. Thermophysical Properties of Aqueous Solution Used as Secondary Working Fluids. Stockholm 2007. Doctoral Thesis, Royal Institute of Technology, 2007.

14. NATERER, G. F. Heat Transfer in Single and Multiphase Systems. Boca Raton: CRC Press, 2003.

15. NIEZGODA-ZELASKO, B., ZELASKO, J. Generalized Non-Newtonian Heat Exchange Flow of Ice Slurry in Pipes. Chemical and Process Engineering, n. 30, pp. 453-473, 2009.

16. PRUZAESKY, F. C., et al. Pasta de gelo e nanofluidos em sistemas de refrigeração. Climatização e Refrigeração, edição n. 96, pp. 47-60, 2008.

17. SECCOOL. Properties. Version 1.33 [S.I.]: Desik Project Group, 2007.

18. SKOVRUP, M. J. SecCool Properties: users manual. Lyngby: IPU \& Department of Mechanical Engineering Technical University of Denmark, 2005.

19. TICONA, E. M. Determinação Experimental das Características de Transferência de Calor de um Gerador de Pasta de Gelo. Rio de Janeiro, 2007. Ph.D. Thesis, Pontifícia Universidade Católica, 2007. 